\title{
Acute and chronic effects of resistance exercise on blood pressure in elderly women and the possible influence of $A C E$ I/D polymorphism
}

This article was published in the following Dove Press journal:

International Journal of General Medicine

II July 2013

Number of times this article has been viewed

\author{
Márcio Rabelo Mota ${ }^{1,3}$ \\ Ricardo Jacó Oliveira ${ }^{2}$ \\ Denize Faria Terra ${ }^{3}$ \\ Emerson Pardono ${ }^{4}$ \\ Maurílio Tiradentes Dutra ${ }^{2}$ \\ Jeeser Alves de Almeida ${ }^{3}$ \\ Francisco Martins Silva ${ }^{3}$ \\ 'University Center of Brasília \\ (UniCeub), Brasília, Brazil; ${ }^{2}$ University \\ of Brasília (UnB), Brasília, Brazil; \\ ${ }^{3}$ Catholic University of Brasília (UCB), \\ Brasília, Brazil; ${ }^{4}$ Federal University of \\ Sergipe (UFS), São Cristóvão, Brazil
}

Correspondence: Jeeser Alves de

Almeida

Catholic University of Brasilia (UCB) QS

07 Lt 01 EPCT - Águas Claras,

71966-700, Brazilia, Brazil

Tel +55 618 2094343

Email jeeser@gmail.com

\begin{abstract}
This study investigated the chronic effect of blood pressure (BP) and post-exercise hypotension $(\mathrm{PEH})$ during resistance training (RT) and its relation with the angiotensinconverting enzyme $(A C E)$ gene insertion/deletion (I/D) polymorphism in hypertensive elderly women. Participants were divided into two groups: an experimental group (EG) with exercise and a control group (CG) without exercise. The EG performed one adaptation month and one repetition maximum load (1RM) test at the end of this period. After the first month, the EG conducted a three-month program of RT at $60 \%, 70 \%$, and $80 \%$ of $1 \mathrm{RM}$, respectively, for each month. The CG was evaluated at the end of each month. Systolic (SBP) and diastolic (DBP) blood pressure (Microlife BP 3AC1-1) were measured, with the subject in a seated position, during an acute session for both GE and CG as follows: every 5 minutes for 20 minutes at preexercise rest, immediately after the resistance exercise and control, and every 15 minutes during 1 hour of recovery after exercise and CG. Analysis of covariance showed reduction in SBP and DBP $(P \leq 0.05)$ rest values after the RT program. PEH was observed only for the EG in acute sessions, for SBP after the second and third months $(P \leq 0.05)$, and for DBP after the second and fourth months $(P \leq 0.05)$. No significant differences in main effects and interaction effects between blood pressure and ACE I/D were observed. The occurrence of chronic reduction of blood pressure and PEH through EG may have a protective effect on the cardiovascular system with no ACE I/D polymorphism influence for this population.
\end{abstract}

Keywords: post-exercise hypotension, resistance exercise, angiotensin-converting enzyme, genetics, polymorphism

\section{Introduction}

Hypertension is a multifactorial and multicausal syndrome characterized by high blood pressure (BP) levels ( $\geq 140 / 90 \mathrm{mmHg}$ ), usually associated with metabolic, hormonal, and structural disorders, and representing a primary risk for coronary disease. ${ }^{1}$ The non-pharmacological treatment of hypertension through physical exercise can produce significant hemodynamic changes including increases in muscle blood flow, nitric oxide production, and $\alpha 1$ and $\alpha 2$ adrenergic receptors density in skeletal muscles. $^{2,3}$

The importance of performing aerobic and resistance exercise to prevent the risk of stroke by the promotion of post-exercise hypotension (PEH) is evidenced by several studies. ${ }^{4-8}$ However, although post-aerobic exercise hypotension is well established, ${ }^{1,9}$ few studies have investigated post-resistance exercise hypotension; those that have show conflicting results, with some studies showing reduction, ${ }^{10-13}$ maintenance, ${ }^{14}$ or even increase ${ }^{15}$ in BP after a resistance exercise session. 
Beyond the multifactorial issues mentioned above, genetic characteristics may be related to blood pressure (BP) and cardiovascular diseases (CVDs). A study conducted with 496 subjects observed associations between CVD and polymorphisms of genes related to the renin-angiotensinaldosterone system (RAAS), ${ }^{16}$ which plays an important role in circulatory homeostasis. In humans, plasma levels of angiotensin-converting enzyme (ACE) may be related to the insertion/deletion (I/D) polymorphism of the $A C E$ gene, located on chromosome $17 .{ }^{17,18}$ Rigat et a ${ }^{18}$ investigated the $A C E$ gene I/D polymorphism in 80 healthy subjects and observed that DD homozygotes showed a greater concentration of circulating ACE than the ID heterozygotes and II homozygotes genotypes. Moreover, another study found a positive association between ACE I/D polymorphism and hypertension. ${ }^{19}$

Floras et $\mathrm{al}^{20}$ observed that the effect of 45 minutes of acute submaximal treadmill exercise on PEH magnitude may be linked both to initial BP levels and to genetic factors. Thus, research on chronic diseases such as hypertension requires a more detailed assessment of gene polymorphisms in RAAS. Taken together, the occurrence of $\mathrm{PEH}$ and the possible association with genetic factors or even with ethnic and genetic factors ${ }^{21}$ would aid in prescribing more precise exercise regimes for elderly.

To the authors' knowledge, there have been no scientific studies relating the decrease in BP after chronic resistance training and ACE I/D polymorphism. It would be useful to analyze the BP throughout a resistance exercise program and its association with ACE I/D polymorphism at different intensities in hypertensive women in order to clarify this issue. Thus, the purpose of this study was to investigate the chronic effect and PEH occurrence during a 4-month period of resistance training and its relation with ACE I/D polymorphism in hypertensive elderly women.

\section{Methods}

\section{Experimental approach to the problem}

Subjects were divided into two groups to perform resistance training (experimental group [EG], $\mathrm{n}=32$ ) and control sessions without exercise (control group [CG], $\mathrm{n}=32$ ) for 16 weeks. The exercise sessions were performed three times per week. Three sets of ten exercises, using an adapted protocol, ${ }^{22}$ were performed in the following order: lat pull-down, knee extension, chest press in a vertical machine, hip abduction, knee flexion, abduction of the shoulders with free weights, free-standing calf raises, sit-ups, trunk extension, and leg press $45^{\circ}$. The velocity of execution adopted was 2 seconds for both concentric and eccentric phases (2:2). Before and after each exercise session, stretching exercises for relevant major muscle groups were performed. Load progression occurred each month in order to respect physiological adaptations, as well as to establish the usefulness of the protocol on the variables measured. The weight machines used were by Righetto ${ }^{\circledR}$ (São Paulo, Brazil), and all tests were conducted around $3 \mathrm{pm}$.

\section{Subjects}

After informed consent was signed, 64 elderly female subjects $(67.1 \pm 6.2$ years; $66.4 \pm 13.4 \mathrm{~kg} ; 142.2 \pm 5.7 \mathrm{~cm})$ were selected to participate (Table 1). The women had been sedentary for at least 6 months and previously diagnosed with hypertension controlled with the use of antihypertensive medication. To participate in the intervention, the subjects underwent a cardiac evaluation consisting of a resting electrocardiogram and an effort test on a treadmill. The study was approved by the ethics committee of the Catholic University of Brasilia, Brasilia, Brazil (process number 075/2006).

\section{Experimental procedures Determination of one repetition maximum (IRM) load}

Tests were conducted as per the protocol of Kraemer and Fry $^{23}$ after 3 weeks of training that aimed to promote neural adaptation and efficiency of motor control..$^{24}$ No 1 RM tests were performed for the abduction of the shoulder, sit-ups, trunk extension, and free-standing calf exercises.

\section{Resistance exercise sessions}

The EG performed 60 sessions of resistance exercise lasting 40 minutes, at the same time of day (2.40 to $4.40 \mathrm{pm})$ on different days, as follows:

- Month 1: subjects were submitted to an adaptation period of 12 sessions of resistance exercise at light intensity, performing ten repetitions in each set with a 30 -second rest interval between sets. At the end of this first month, 1RM was applied as per the previous description.

- Month 2: 16 sessions of resistance exercise at $60 \%$ of $1 \mathrm{RM} ; 12$ repetitions with a 60 -second rest interval between sets.

- Month 3: 16 sessions of resistance exercise at $70 \%$ of $1 \mathrm{RM}$; ten repetitions with a 60 -second rest interval between sets.

- Month 4: 16 sessions of resistance exercise at 80\% of 1RM; eight repetitions with a 90 -second rest interval between sets.

\section{Extraction of DNA: genotyping}

Venous blood samples $(5 \mathrm{~mL})$ were collected from the antecubital vein of each subject, drawn by a specialized 
Table I Descriptive characteristics of experimental (EG) and control (CG) groups $(n=64)$

\begin{tabular}{|c|c|c|c|c|}
\hline Patient & EG & CG & $T$-value & $P$-value \\
\hline characteristics & $\mathrm{n}=32$ & $\mathrm{n}=\mathbf{3 2}$ & & \\
\hline II genotype (n) & 11 & 10 & - & - \\
\hline ID genotype (n) & 9 & 11 & - & - \\
\hline DD genotype (n) & 12 & 11 & - & - \\
\hline Age (years) & $67.5 \pm 7.0$ & $66.8 \pm 5.4$ & 0.49 & 0.63 \\
\hline Body weight (kg) & $65.4 \pm 14.3$ & $67.4 \pm 12.6$ & -0.62 & 0.54 \\
\hline Height $(\mathrm{cm})$ & $153.3 \pm 5.9$ & $151.2 \pm 6.2$ & 1.42 & 0.16 \\
\hline BMI $\left(\mathrm{kg} \cdot\left[\mathrm{m}^{2}\right]^{-1}\right)$ & $27.8 \pm 5.5$ & $29.4 \pm 4.6$ & -1.32 & 0.19 \\
\hline Resting SBP (mmHg) & $134.5 \pm 14.6$ & $131.8 \pm 16.9$ & 0.67 & 0.51 \\
\hline Resting DBP (mmHg) & $76.0 \pm 9.2$ & $74.3 \pm 7.4$ & 0.82 & 0.42 \\
\hline Resting MBP (mmHg) & $94.9 \pm 10.0$ & $93.4 \pm 9.5$ & -0.54 & 0.59 \\
\hline Resting HR (bpm) & $72.2 \pm 13.5$ & $73.7 \pm 9.4$ & -0.33 & 0.75 \\
\hline Resting DP (mmHg · bpm) & $9544.3 \pm 1927.0$ & $9686.9 \pm 1549.1$ & 0.63 & 0.53 \\
\hline
\end{tabular}

Notes: Data are presented as mean \pm standard deviation. II genotype: two alleles with 287 bp insertion in ACE gene; DD genotype: two alleles with 287 bp deletion in ACE gene; ID genotype: one allele with 287 bp insertion and one allele with 287 bp deletion in ACE gene.

Abbreviations: BMI, body mass index; DBP, diastolic blood pressure; DP, double product; HR, heart rate; MBP, mean blood pressure; SBP, systolic blood pressure.

professional and stored in sterile vacuum tubes containing ethylenediamine tetraacetic acid (EDTA) anticoagulant. Then, DNA extraction was performed by the salting-out method, ${ }^{25}$ and high-molecular weight genomic DNA was extracted from peripheral leukocytes. The method used for DNA quantification was electrophoresis on agarose gel $(1 \%)$, stained with $3 \mu \mathrm{L}$ of ethidium bromide to estimate the concentration of DNA extracted in advance.

DNA amplification: polymerase chain reaction (PCR) For DNA amplification, the PCR technique, which amplifies the DNA fragment containing the insertion polymorphism, was applied. The methodology of Zhao et $\mathrm{a}^{26}$ was adopted to assess the direct (forward) and reverse primers.

\section{Classification of ACE gene polymorphism}

The samples were classified by PCR into one of three possible genotypes for the polymorphism of ACE: two homozygotes (DD and II) and one heterozygote (ID). By ultraviolet light after electrophoresis at $80 \mathrm{~V}$ in $1 \%$ agarose gel, it was possible to visualize the PCR products. The identification of genotypes was performed by viewing the presence of the alleles D and I; the presence of only a fragment of 190 base pairs characterizes the DD genotype and the presence of only a fragment of 490 base pairs characterizes the II genotype. The ID heterozygotes were identified by the presence of both fragments. The analysis of genotype identification was performed separately by two researchers. To increase the specificity of genotyping, an additional confirmatory PCR was performed with all samples carrying the DD genotype, using a pair of primers specific for the insertion, as used in previous studies. ${ }^{27,28}$ Samples carrying the ID or II genotype were used as positive controls during this reamplification.

\section{Procedure for measurements of $\mathrm{BP}$ and heart rate $(H R)$}

Measurements of systolic (SBP) and diastolic (DBP) BP were evaluated using an automatic BP device (BP 3AC1-1; Microlife, Switzerland) following the guidelines of a previous study. ${ }^{29} \mathrm{HR}$ was measured using a specific monitor (FS 3, Polar Sport Tester, Finland). The variables were measured with the subject in a seated position at the end of each month for both GE and CG as follows:

- EG: measurement of BP and HR every 5 minutes for 20 minutes at pre-exercise rest, as well as during and immediately after resistance exercise, and every 15 minutes during 1 hour of post-exercise recovery.

- CG: measurement of BP and HR every 5 minutes for 20 minutes at rest before the session, as well as immediately after and every 15 minutes for 1 hour after the control session.

\section{Statistical analyses}

Statistical analyses were performed using Statistical Package for Social Sciences (SPSS) for Windows (v 10.0; IBM Corporation, Armonk, NY, USA). The descriptive analyses were presented as mean \pm standard deviation (SD). The assessment of normality was obtained by analyses of skewness and the Kolmogorov-Smirnov test. To analyze homoscedasticity, the Levene's test was applied.

Analysis of variance (ANOVA) for repeated measures and Bonferroni test of multiple comparisons were adopted to 
verify the chronic effect on BP and PEH at different moments in the months of training in the EG and CG. The Student's $t$-test for independent samples was applied to assess differences between the groups. Finally, an analysis of covariance ([ANCOVA] group versus genotype versus months of training time) was applied with the Bonferroni post hoc test to analyze the effects of training on SBP and DBP. The level of significance adopted was $P \leq 0.05$.

\section{Results}

Both SBP and DBP were reduced with resistance training when the rest values from the first and fourth months were compared (Tables 2 and $3 ; P \leq 0.05$ ). PEH was observed after acute sessions at the end of the second and third months for SBP analysis $(\mathrm{F}[15.930]=14.5, P=0.001)$ for EG. At months 1 and 2, SBP did not differ between groups. At the acute session at the end of month 3, there was a significant difference between groups in the recovery period of $30(P=0.009)$ and $45(P=0.05)$ minutes. At month 4 , significant differences between groups at all times of recovery were observed $(P \leq 0.05)$. The $\mathrm{CG}$ showed neither $\mathrm{PEH}$ nor differences among the rest $\mathrm{BP}$ in the 4 months (Table 2). The differences in SBP in the EG and CG are shown in Table 2.

PEH for DBP was observed after the acute sessions at the end of the second and fourth months for the EG $(\mathrm{F}[15.930]=7.10 ; P=0.001)$. At month 1 , there was no significant difference between groups. At month 2 , there were significant differences between groups at rest $(P=0.001)$ and at the recovery period of $60 \mathrm{~min}$ utes $(P=0.001)$. At months 3 and 4 , there were no significant differences between groups. The CG showed neither PEH nor differences among the rest BP for the four months (Table 3). DBP analyses are also shown in Table 3.

The SBP and DBP responses during resistance training and in the control group without exercise, and their interactions to the ACE I/D polymorphism are showed in Tables 4 and 5 , respectively. An influence of rest DBP values was observed by months $(\mathrm{F}[1.54]=108.76 ; P=0.001)$ and used as a covariate to the ACE I/D polymorphism interactions. ANCOVA did not show difference in main effects and interaction effects of the ACE I/D polymorphism and PEH for both SBP and DBP (Tables 4 and 5, respectively) for the EG and the CG.

\section{Discussion}

This study evaluated the chronic effects of resistance exercises on BP and the PEH (acute effect) during resistance training in hypertensive physically inactive women aged 60-75 years; the possible relation between $\mathrm{PEH}$ and the ACE I/D polymorphism was also investigated. Our main findings were that ANCOVA showed a chronic reduction in rest values of SBP and DBP only for the EG (Tables 2 and $3 ; P \leq 0.05)$. Also, PEH was observed only for the $\mathrm{EG}$ at acute seccions, for SBP after the second and third months (Table $2 ; P \leq 0.05$ ) and for DBP after the second and fourth months (Table $3 ; P \leq 0.05$ ). No significant differences in main effects and interaction effects between BP and genotypes were observed (Tables 4 and 5). These chronic and acute patterns were not evidenced in the $\mathrm{CG}$.

The findings of this study about the response of SBP to resistance exercise corroborate the results in the scientific literature about the acute ${ }^{7,30}$ and chronic ${ }^{12,22,31}$ benefits of this type of exercise. We found magnitude of decrease in the PEH of approximately $13.0 \mathrm{mmHg}$ in month 2 and about $5.6 \mathrm{mmHg}$ in month 3 for SBP in the EG (Table 2).

Table 2 Systolic blood pressure responses $(\mathrm{mmHg})$ in the experimental $(\mathrm{EG})$ and control $(\mathrm{CG})$ groups

\begin{tabular}{|c|c|c|c|c|c|}
\hline \multirow[t]{2}{*}{ Month } & \multirow[t]{2}{*}{ Rest } & \multicolumn{4}{|c|}{ Recovery period } \\
\hline & & 15 minutes & 30 minutes & 45 minutes & 60 minutes \\
\hline \multicolumn{6}{|l|}{ EG } \\
\hline I & $134.5 \pm 14.6$ & $133.6 \pm 13.6$ & $132.2 \pm 13.4$ & $132.2 \pm 13.5$ & $133.5 \pm 12.6$ \\
\hline 2 & $134.5 \pm 14.6$ & $126.4 \pm 16.5^{*, \infty}$ & $122.4 \pm 13.8^{*, \infty}$ & $|2| .5 \pm \mid 4.8^{*, \infty}$ & $128.2 \pm 14.4^{*, \infty}$ \\
\hline 3 & $124.9 \pm 11.8^{\infty, \dagger}$ & $121.6 \pm 11.9^{\infty, \dagger}$ & $119.3 \pm 13.0^{*}, \infty$ & $120.9 \pm 14.1^{\infty}$ & $122.8 \pm 14.0^{\infty, \dagger}$ \\
\hline 4 & $120.2 \pm 1 \mid .8^{\infty, \dagger, \phi}$ & $118.8 \pm 11.7^{\infty, \dagger}$ & $117.5 \pm 12.1^{\infty}$ & $117.9 \pm 11.4^{\infty}$ & $120.3 \pm 12.0^{\infty, \dagger}$ \\
\hline \multicolumn{6}{|l|}{ CG } \\
\hline 1 & $131.8 \pm 16.9$ & $127.6 \pm 16.6$ & $129.7 \pm 17.0$ & $128.2 \pm 18.1$ & $127.8 \pm 16.8$ \\
\hline 2 & $129.1 \pm 15.8$ & $128.8 \pm 18.7$ & $129.6 \pm 17.3$ & $128.6 \pm 16.6$ & $127.8 \pm 16.8$ \\
\hline 3 & $129.1 \pm 15.8$ & $128.7 \pm 18.7$ & $129.6 \pm 17.3^{\#}$ & $128.6 \pm 16.7^{\#}$ & $128.4 \pm 18.0$ \\
\hline 4 & $132.3 \pm 17.6$ & $130.4 \pm 19.9^{\#}$ & $128.7 \pm 18.3^{\#}$ & $128.2 \pm 19.5^{\#}$ & $127.7 \pm 16.7^{\#}$ \\
\hline
\end{tabular}

Notes: Data are presented as mean \pm standard deviation. $* P \leq 0.05$ in relation to rest; ${ }^{\circ} P \leq 0.05$ in relation to month 1 ; ${ }^{\dagger} P \leq 0.05$ in relation to month 2 ; ${ }^{\text {a } P} \leq 0.05$ in relation to month $3 ; \# P \leq 0.05$ in relation to the same moments in EG. 
Table 3 Diastolic blood pressure responses $(\mathrm{mmHg})$ in the experimental $(\mathrm{EG})$ and control $(\mathrm{CG})$ groups

\begin{tabular}{|c|c|c|c|c|c|}
\hline \multirow[t]{2}{*}{ Month } & \multirow[t]{2}{*}{ Rest } & \multicolumn{4}{|c|}{ Recovery period } \\
\hline & & 15 minutes & 30 minutes & 45 minutes & 60 minutes \\
\hline \multicolumn{6}{|l|}{ EG } \\
\hline 1 & $76.0 \pm 9.2$ & $75.4 \pm 10.0$ & $74.5 \pm 11.3$ & $73.9 \pm 9.6$ & $76.5 \pm 10.1$ \\
\hline 2 & $80.9 \pm 11.1^{\infty}$ & $73.0 \pm 10.0^{*}$ & $73.2 \pm 9.5^{*}$ & $75.9 \pm 9.9 *$ & $81.0 \pm 11.1^{\infty}$ \\
\hline 3 & $74.5 \pm 9.5^{\dagger}$ & $74.5 \pm 9.5$ & $74.2 \pm 9.5$ & $74.2 \pm 9.5$ & $74.1 \pm 9.5^{\infty, \dagger}$ \\
\hline 4 & $72.4 \pm 9.3^{\infty, \dagger}$ & $72.2 \pm 10.3$ & $69.7 \pm 9.2^{*, \infty, \uparrow, \alpha}$ & $70.3 \pm 9.7^{*, \infty, \dagger, \alpha}$ & $72.5 \pm 10.1^{\infty, t}$ \\
\hline \multicolumn{6}{|l|}{ CG } \\
\hline I & $74.3 \pm 7.4$ & $72.5 \pm 7.2$ & $74.0 \pm 7.8$ & $73.4 \pm 7.6$ & $73.3 \pm 7.5$ \\
\hline 2 & $73.0 \pm 7.2^{\#}$ & $72.9 \pm 7.9$ & $72.1 \pm 7.8$ & $72.6 \pm 8.0$ & $72.7 \pm 6.9^{\#}$ \\
\hline 3 & $73.5 \pm 7.4$ & $72.8 \pm 8.1$ & $72.2 \pm 8.1$ & $72.6 \pm 7.1$ & $72.2 \pm 7.6$ \\
\hline 4 & $73.8 \pm 7.8$ & $73.7 \pm 7.9$ & $73.6 \pm 8.6$ & $73.5 \pm 8.4$ & $72.8 \pm 8.4$ \\
\hline
\end{tabular}

Notes: Data are presented as mean \pm standard deviation. $* P \leq 0.05$ in relation to rest; ${ }^{\infty} P \leq 0.05$ in relation to month $\mathrm{I}$; ${ }^{\dagger} P \leq 0.05$ in relation to month 2 ; ${ }^{\text {a }} P \leq 0.05$ in relation to month $3 ;{ }^{\# P} \leq 0.05$ in relation to the same moments in EG.

In regard to our DBP results, there were significant reductions in moments of acute post-exercise, similar to the results of other studies. ${ }^{20,32}$ In general, we observed a PEH magnitude of approximately $7.9 \mathrm{mmHg}$ in month 2 and about $2.7 \mathrm{mmHg}$ in month 4 for the subjects who trained (Table 3).

It is clear from the literature that PEH is an acute benefit from physical exercise. Its mechanisms are not clear, but may be related to multifactorial origins. ${ }^{21}$ Anyway, reductions in sympathetic activation, in cardiac output and the maintenance of the peripheral vascular resistance that decrease after exercise, may be the physiological mechanisms to promote PEH. ${ }^{1,9,33}$

The average reduction in SBP at the end of the training period was $14.3 \mathrm{mmHg}$, a relevant result with regard to non-pharmacological approaches for prevention, treatment, and control of hypertension in elderly women. A population study conducted by Stamler ${ }^{33}$ showed that small decreases in BP can protect the cardiovascular system. Reductions in SBP of 2-5 mmHg may decrease the risk of infarction in $6 \%-14 \%$ and the risk of coronary heart disease in $4 \%-9 \%$, also reducing mortality from all causes by $3 \%-7 \%$. These data are relevant when analyzing the results of the present study, in which a significant

Table 4 ANCOVA results and their interactions with SBP

\begin{tabular}{llll}
\hline Variables & F-value & $P$-value & $\eta^{2}$ \\
\hline Genotypes & 0.55 & 0.58 & 0.020 \\
Groups $\times$ genotypes $\times$ PEH & 1.26 & 0.23 & 0.105 \\
Groups $\times$ genotypes $\times$ months & 1.53 & 0.13 & 0.124 \\
Groups $\times$ genotypes $\times$ PEH $\times$ months & 1.31 & 0.12 & 0.108 \\
\hline
\end{tabular}

Abbreviations: ANCOVA, analysis of covariance; $\mathrm{PEH}$ : post-exercise hypotension; SBP, systolic blood pressure. reduction in SBP of approximately $14.0 \mathrm{mmHg}$ as a result of chronic resistance training for 4 months was observed. Additionally, a chronic reduction of $3.6 \mathrm{mmHg}$ was observed in the EG. This chronic effect reinforces the importance of resistance training in order to prevent hypertension and promote the health of elderly hypertensive people.

Our results from SBP and DBP responses after resistance exercise and control sessions showed no relation to the ACE I/D polymorphism (Tables 4 and 5). In fact, ACE I/D polymorphism and PEH of SBP showed a tendency of association only at month 2, with more PEH for the II genotype subjects.

Although the training protocols were different, our findings corroborate to some extent the results of Dengel et al, ${ }^{34}$ which showed no significant interaction between genotype and aerobic training in relation to SBP, DBP, and mean BP. To the contrary, relatively recent results ${ }^{35,36}$ showed that 10 weeks of training on a cycle ergometer (aerobic exercise) significantly decreased the levels of SBP and DBP only in patients with genotypes II and ID, and not in the subjects with the DD genotype of $A C E$.

Despite the absence of association between ACE I/D genotypes and DBP in our study, Blanchard et $\mathrm{al}^{37}$ showed

Table 5 ANCOVA results and their interactions with DBP

\begin{tabular}{llll}
\hline Variables & F-value & $P$-value & $\eta^{2}$ \\
\hline Genotypes & 2.99 & 0.06 & 0.100 \\
Groups $\times$ genotypes $\times$ PEH & 1.15 & 0.32 & 0.096 \\
Groups $\times$ genotypes $\times$ months & 1.03 & 0.42 & 0.087 \\
Groups $\times$ genotypes $\times$ PEH $\times$ months & 0.92 & 0.57 & 0.079 \\
\hline
\end{tabular}

Abbreviations: ANCOVA, analysis of covariance; DBP, diastolic blood pressure; $\mathrm{PEH}$, post-exercise hypotension. 
a greater DBP drop in subjects with DD genotype in relation to genotypes II and ID after mild aerobic training at $40 \% \mathrm{VO}_{2}$ max for men after aerobic exercise. The study by $\mathrm{Kim}^{38}$ was closer to ours in regard to population evaluated and type of exercise, but not with respect to the result. This author observed that, in adult women, the DD genotype showed greater reduction of DBP, compared to the II group, when performing aerobic and resistance exercise two to three times a week.

The I/D polymorphism of the $A C E$ gene might be related to different effects of resistance exercise related to health, such as strength gains, muscle hypertrophy, ${ }^{38,39}$ and $\mathrm{BP}$ response to exercise. ${ }^{40}$ In addition, it appears that the DD genotype of the $A C E$ gene is associated with a higher incidence of hypertension. ${ }^{41}$ Investigations on the interaction of different I/D genotypes of $A C E$ in response to resistance exercise are of great importance in regard to health promotion in the general population and particularly in the elderly, who are prone to development of hypertension. However, the present study showed only a tendency of PEH to be different between the DD and ID genotypes to the SBP in the second month of training, showing differences neither in the interaction between the II, ID, and DD $A C E$ genotypes in relation to SBP in other months nor to DBP.

There are a small number of papers linking ACE I/D polymorphism to resistance training, which limits the discussion of our findings. ${ }^{38,39}$ It is also relevant to mention the limitations of the present study due to the sample characteristics. It is possible that environmental factors may have influenced the results and hindered a proper association between the variables investigated. Also, more participants in the ACE activity analysis, and in other polymorphisms, could provide better interpretations. In addition, diet and hydration were not rigorously controlled. These facts reinforce the need for future studies.

In summary, chronic reductions of resting $\mathrm{BP}$ and $\mathrm{PEH}$ after acute sessions during the resistance training were evidenced, which may be interpreted as a protective effect on the cardiovascular system for elderly hypertensive women. Finally, there were no significant associations between $\mathrm{PEH}$ and the ACE I/D polymorphism.

\section{Practical applications}

Our findings may contribute to promoting chronic reductions on resting $\mathrm{BP}$ values and $\mathrm{PEH}$ (acute reductions on $\mathrm{BP}$ ) obtained from resistance exercise training for the hypertensive population. In addition, the progression of loads adopted in the present study (light loads at adaptation period; $60 \% 1 \mathrm{RM}$ at month $2 ; 70 \% 1 \mathrm{RM}$ at month 3 ; and $80 \% 1 \mathrm{RM}$ at month 4) may be helpful to professionals who want to guarantee cardiovascular safety and strength gains in a hypertensive elderly population.

\section{Disclosure}

The authors report no conflicts of interest in this work.

\section{References}

1. Halliwill JR. Mechanisms and clinical implications of post-exercise hypotension in humans. Exerc Sport Sci Rev. 2001;29(2):65-70.

2. Stamler SJ, Meissner G. Physiology of nitric oxide in skeletal muscle. Physiol Rev. 2001;81(1):209-237.

3. Trombetta IC, Batalha LT, Rondon MU, et al. Weight loss improves neurovascular and muscle metaboreflex control in obesity. Am J Physiol Heart Circ Physiol. 2003;285:974-982.

4. Fitzgerald W. Labile hypertension and jogging: new diagnostic tool or spurious discovery? Br Med J (Clin Res Ed). 1981;282: 542-544.

5. Hill L. Arterial pressure in man while sleeping, resting, working and bathing. J Physiol (Lond). 1897;22:26-29.

6. MacDonald JR, Hogben CD, Tarnopolsky MA, MacDougall JD. Post exercise hypotension is sustained during subsequent bouts of mild exercise and simulated activities of daily living. J Hum Hypertens. 2001;15(8):567-571.

7. Mota MR, Pardono E, Lima LC, et al. Effects of treadmill running and resistance exercises on lowering blood pressure during the daily work of hypertensive subjects. J Strength Cond Res. 2009;23(8):2331-2338.

8. Schneider EC, Truesdell D. A statistical study of the pulse rate and the arterial blood pressures in recumbence, standing, and after a standard exercise. Am J Physiol. 1922;61:29-74.

9. Brandão Rondon MU, Alves MJ, Braga AM, et al. Postexercise blood pressure reduction in elderly hypertensive patients. J Am Coll Cardiol. 2002;39(4):676-682.

10. Carter JR, Ray CA, Downs EM, Cooke WH. Strength training reduces arterial blood pressure but not sympathetic neural activity in young normotensive subjects. J Appl Physiol. 2003;94:2212-2216.

11. Moraes MR, Bacurau RFP, Ramalho JDS, et al. Increase in kinins on post-exercise hypotension in normotensive and hypertensive volunteers. Biol Chem. 2007;388(5):533-540.

12. Queiroz ACC, Gagliardi JF, Forjaz CL, Rezk CC. Clinic and ambulatory blood pressure responses after resistance exercise. J Strength Cond Res. 2009;23(2):571-578.

13. Rezk CC, Marrache RC, Tinucci T, Mion D Jr, Forjaz CL. Post-resistance exercise hypotension, hemodynamics, and heart rate variability: influence of exercise intensity. Eur J Appl Physiol. 2006; 98(1):105-112.

14. Roltsch MH, Mendez T, Wilund KR, Hagberg JM. Acute resistive exercise does not affect ambulatory blood pressure in young men and women. Med Sci Sports Exerc. 2001;33(6):881-886.

15. Focht BC, Koltyn KF. Influence of resistance exercise of different intensities on state anxiety and blood pressure. Med Sci Sports Exerc. 1999;31(3):456-463.

16. Cheng S, Grow MA, Pallaud C, et al. A multilocus genotyping assay for candidate markers of cardiovascular disease risk. Genome Res. 1999;9: 936-949.

17. Mattei MG, Hubert C, Alhenc-Gelas F, Roeckel N, Corvol P, Soubrier F. Angiotensin I converting enzyme gene is on chromosome 17. Cytogenet Cell Genet. 1989;51:1041.

18. Rigat B, Hubert C, Alhenc-Gelas F, Cambien F, Corvol P, Soubrier F. An insertion/deletion polymorphism in the angiotensin I-converting enzyme gene accounting for half the variance of serum enzyme levels. J Clin Invest. 1990;86(4):1343-1346. 
19. Zee RY, Lou YK, Griffiths LR, Morris BJ. Association of a polymorphism of the angiotensin I-converting enzyme gene with essential hypertension. Biochem Biophys Res Commun. 1992;184:9-15.

20. Floras JS, Sinkey CA, Aylward PE, Seals DR, Thoren PN, Mark AL. Postexercise hypotension and sympathoinhibition in borderline hypertensive men [abstract]. Hypertension. 1989;14:28-35.

21. Pardono E, Almeida MB, Bastos AA, Simões HG. Post-exercise hypotension: possible relationship with ethnic and genetic factors. Rev Bras Cineantropom Desempenho Hum. 2012;14(3):353-361.

22. Terra DF, Mota MR, Rabelo HT, et al. Reduction of arterial pressure and double product at rest after resistance exercise training in elderly hypertensive women. Arq Bras Cardiol. 2008;91:299-305. English and Portuguese.

23. Kraemer WJ, Fry AC. Strength testing: development and evaluation of methodology. In: Maud PJ, Fosters C, editors. Physiological Assessment of Human Fitness. Champaign, IL: Human Kinetics; 1995:115-135.

24. Galvão DA, Taaffe DR. Single- vs multiple-set resistance training: recent developments in the controversy. J Strength Cond Res. 2004; 18(3):660-667.

25. Miller SA, Dykes DD, Polesky HF. A simple salting out procedure for extracting DNA from human nucleated cells. Nucl Acids Res. 1988; $16(3): 1215$.

26. Zhao B, Moochhala SM, Tham Sy, et al. Relationship between angiotensin-converting enzyme ID polymorphism and VO2 max of Chinese males. Life Sci. 2003;73:2625-2630.

27. Gonzáles AJ, Hernández D, De Vera A, et al. ACE gene polymorphism and erythropoietin in endurance athletes at moderate altitude. Med Sci Sports Exerc. 2006;38(4):688-693.

28. Shanmugan V, Sell KW, Saha BK. Mistyping ACE heterozygotes. Genome Res. 1993;3:120-121.

29. Cuckson AC, Reinders A, Shabeeh H, Shennan AH; British Hypertension Society. Validation of the Microlife BP 3BTO-A oscillometric blood pressure monitoring device according to a modified British Hypertension Society protocol. Blood Press Monit. 2002;7(6):319-324.

30. Lizardo FHJ, Simões GH. Efeitos de diferentes sessões de exercícios resistidos sobre a hipotensão pós-exercício [Effects of different resistance exercise sessions on post-exercise hypotension]. Rev Bras Fisioter. 2005;9: 249-255. Portuguese.
31. Kelley AG, Kelley SK. Progressive resistance exercise and resting blood pressure: a meta-analysis of randomized controlled trials. Hypertension. 2000;35:838-843.

32. Cléroux J, Kouamé N, Nadeau A, Coulombe D, Lacourcière Y. Aftereffects of exercise on regional and systemic hemodynamics in hypertension. Hypertension. 1992;19:183-191.

33. Stamler R. Implications of the INTERSALT study. Hypertension. 1991;17(Suppl 1):I16-I20.

34. Dengel DR, Brown MD, Ferrell RE, Reynolds TH, Supiano M. Exercise induced changes in insulin action are associated with ACE gene polymorphisms in older adults. Physiol Genomics. 2002;11:73-80.

35. Rice T, An P, Gagnon J, et al. Heritability of HR and BP response to exercise training in the HERITAGE Family Study. Med Sci Sports Exerc. 2002;34(6):972-979.

36. Zhang B, Sakai T, Miura S. Association of angiotensin-convertingenzyme gene polymorphism with the depressor response to mild exercise therapy in patients with mild to moderate essential hypertension. Clin Genet. 2002;62:328-333.

37. Blanchard BE, Tsongalis GJ, Guidry MA, et al. RAAS polymorphisms alter the acute blood pressure response to aerobic exercise among men with hypertension. Eur J Appl Physiol. 2006;97(1):26-33.

38. Kim K. Association of angiotensin-converting enzyme insertion/ deletion polymorphism with obesity, cardiovascular risk factors and exercise-mediated changes in Korean women. Eur J Appl Physiol. 2009;105:879-887.

39. Colakoglu M, Cam F, Kayitken B, et al. ACE genotype may have no effect on single versus multiple set preferences in strength training. Eur J Appl Physiol. 2005;95(1):20-26.

40. Folland J, Leach B, Little T, et al. Angiotensin-converting enzyme genotype affects the response of human skeletal muscle to functional overload. Exp Physiol. 2000;85:575-579.

41. Di Pasquale P, Cannizzaro S, Paterna S. Does angiotensin-converting enzyme gene polymorphism affect blood pressure? Findings after 6 years of follow-up in healthy subjects. Eur J Heart Fail. 2004;6:11-16.
International Journal of General Medicine

\section{Publish your work in this journal}

The International Journal of General Medicine is an international peer-reviewed open-access journal that focuses on general and internal medicine, pathogenesis, epidemiology, diagnosis, monitoring and treatment protocols. The journal is characterized by the rapid reporting of reviews, original research and clinical studies across all disease areas.

\section{Dovepress}

A key focus is the elucidation of disease processes and management protocols resulting in improved outcomes for the patient.The manuscript management system is completely online and includes a very quick and fair peer-review system. Visit http://www.dovepress.com/ testimonials.php to read real quotes from published authors. 